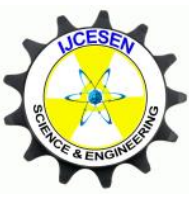

Copyright (C) IJCESEN
International Journal of Computational and

Experimental $\boldsymbol{S}$ cience and Engineering

(IJCESEN)

Vol. 3-No.1 (2017) pp. 38-43

http://iakkurt.dergipark.gov.tr/ijcesen

Research Article

\title{
Konik Kanatlı Yatay Borunun Farklı Kanat Aralıklarındaki Isıl Performansının Deneysel Olarak Araştırılması \#
}

\author{
Gülay YAKAR* \\ Pamukkale Üniversity, Mechanical Engineering Department, 20100, Denizli-Turkey \\ * Corresponding Author : gyakar@pau.edu.tr \\ (First received 25 November 2016 and in final form 20 April 2017) \\ \# Presented in " ${ }^{\text {rd }}$ International Conference on Computational and Experimental Science and Engineering (ICCESEN-2016)"
}

Anahtar Kelimeler
Konik kanat
Kanat aralığ 1
Etkinlik

Keywords

Conical fin

Fin spacing

Effectiveness

\begin{abstract}
Özet: Bu çalışmada, farklı kanat aralıklarına sahip konik kanatlı yatay boruların ısıl performansı deneysel olarak araştırılmıştır. Deneyler üç farklı kanat aralığında (10, 12 ve $15 \mathrm{~mm}$ ) gerçekleştirilmiştir. Çalışma akışkanları olarak, su (1sıtan) ve hava (1sıtılan) kullanılmıştır. Isıtıcı akışkan sıcaklığı $65^{\circ} \mathrm{C}$ değerinde sabit tutulmuştur. Deneylerde eğilme açısı $60^{\circ}$ olan konik kanatlar kullanılmıştır. Soğuk akışkanın sekiz farklı hava hızında $(2-20 \mathrm{~m} / \mathrm{s})$ test bölümüne girmesi sağlanmıştır. Deneysel sonuçlara göre, $R e=$ 50000 değerine kadar 12 ve 15 mm'e ait Nusselt sayılarının hemen hemen birbirine yakın olduğu, $R e=50000$ değerinden sonra ise $12 \mathrm{~mm}$ 'in değerlerinin daha yüksek olduğu tespit edilmiştir. Ayrıca tüm Reynolds sayıları için en düşük Nusselt sayıları 10 mm'de elde edilmiştir.
\end{abstract}

\begin{abstract}
In this paper, thermal performance of horizontal tube with conical fins was studied experimentally for different fin spacings. Experiments were carried out for three different fin spacings (10, 12 and $15 \mathrm{~mm})$. Water as hot fluid and air as cold fluid were used. Hot fluid temperature was fixed as $65^{\circ} \mathrm{C}$. In the experiments, conical fins with $60^{\circ}$ inclination angle were used. The cold fluid was entered to the test section at eight different air flow velocities $(2-20 \mathrm{~m} / \mathrm{s})$. Experimental results indicated that the Nusselt numbers of $12 \mathrm{~mm}$ were higher than the others for $\operatorname{Re}>50000$, while the Nusselt numbers of 12 and $15 \mathrm{~mm}$ were almost the same for $\mathrm{Re}<50000$. Moreover, It was determined that the lowest Nusselt numbers were obtained at $10 \mathrm{~mm}$ for all the Reynolds numbers.
\end{abstract}

\section{Giriş}

Enerjinin verimli kullanılması için çözümlerden biri; akışkana bir ilave enerji verilmeden 1 sı geçişinin iyileştirilmesidir. $\mathrm{Bu}$ amaçla, $1 \mathrm{~s} 1$ geçiş yüzeyinin artırılması ve akışın yönlendirilmesi gibi yöntemler çalışılmaktadır.

Ahmed ve diğ. [1] vorteks üreticileri ve nanoakışkanları birlikte kullanarak, bir eşkenar üçgen kanalda laminar 1sı transferini ve akışkanın akış karakterlerini incelemek için sayısal ve deneysel çalışma yapmışlardır. Onların hem sayısal hem de deneysel sonuçları, akışkan temelli vorteks üreticilerin 1sı transferinde önemli derecede artış sağladığını göstermiştir. Tian ve diğ. [2] Kanata yerleștirilen çok sıralı üçgen kanatçıklı düz kanatların akış ve 1S1 transferi karakterlerini incelemek için üç boyutlu sayısal analiz gerçekleştirmişlerdir. Şahin ve diğ. [3] çalışmalarında, helisel türbülatörlü 1 1S1 değiştiricilerinin 1sı transfer performansını ve sürtünme karakterlerini, deneysel ve nümerik olarak araştırmışlardır. Yakar ve Karabacak [4] delinmiş kanatlı 1S1 değiştiricilerinin 1sıl performansını deneysel olarak çalışmışlardır. Deneyleri, altı farklı açısal konumda gerçekleştirmişler ve en iyi açısal konumun $60^{\circ}$ olduğunu belirlemişlerdir. Promvonge ve diğ. [5] borulu 1sı değiştiricisi içine yerleştirilmiş eğilmiş at nalı saptırıcıların, 1sı transferi, sürtünme faktörü ve isıl iyileşme faktörüne etkisini deneysel olarak belirlemişlerdir. Anvari ve diğ. [6] Konik boru eklentili yatay borularda suyun zorlanmış taşınımını deneysel olarak çalışmışlardır. Onlar, deneysel sonuçlardan Nusselt sayısına ait iki adet 
denklem elde etmişlerdir. Lee ve diğ. [7] dairesel kanatlı boru 1s1 değiştiricilerinin taşınımla 1S1 transferi performansında, delinmiş dairesel kanatlı borunun etkisini göstermişlerdir. Yaghoubi ve Mandavi [8] yatay bir silindir üzerine halka şeklinde monte edilmiş kanatlardan, doğal taşınımla ve 1şınımla gerçekleşen 1S1 transferini deneysel ve sayısal olarak çalışmışlardır.

$\mathrm{Bu}$ çalışmanın amacı, ısı transferi açısından en iyi kanat aralığını belirlemektir. Çalışmada kullanılan konik kanatlar hem 1sı transfer yüzey alanını artırmakta hem de isıtılan akışkanın sıcak yüzeyle temas süresini uzatmaktadırlar. Böylece, 1sı transferi bu iki duruma bağlı olarak artmaktadır.

\section{Deneysel Düzenek}

Deneysel düzeneğin şematik gösterimi Şekil 1'de görülmektedir.

Şekil 1'de görülen deneysel düzenekte; hava, hızı ayarlanabilen bir fan (numara 2) vasitasiyla test bölümüne (numara 7) yönlendirilmiştir. Hava kanalı (numara 3), test bölümü girişinde tam gelişmiş koşullarda akış elde edecek kadar uzun yapılmıştır. Havanın test bölümüne giriş ve çıkıştaki kütlesel debisi, pervane tipi bir debi ölçer (numara 4 ve numara 14) ile belirlenmiştir. Hava akış hızı fan tarafından ayarlanmıştır. Giriş ve çıkıştaki hava sıcaklıkları T tipi bakır - konstantin ssıl çift (numara 5 ve numara 13) tarafindan ölçülmüştür. Kanat dibi $\left(T_{s}\right)$ ve kanatlar arasindaki sicakliklar $\left(T_{\infty}\right)$ da yine aynı tip 1sıl çift ile test bölümü boyunca 15,45 ve 75 $\mathrm{cm}$ mesafelerinde ölçülmüştür. Havanın test bölümüne giriş ve çıkıştaki basınç farkı bir manometre (numara 6 ve numara 12) ile belirlenmiştir. İçinden suyun geçtiği iç boru malzemesi galvanizli çelik kullanılmıştır (numara 8). Kanat malzemesi de yine galvanizli çelik olarak seçilmiştir. Ayrıca, 1sıtma suyunun 1sıtıcı girişinde ve çıkışında basıncı (numara 9 ve numara 10), sicaklığ1 (numara 10 ve numara 17) ve hacimsel debisi (numara 11 ve numara 18) ölçülmüştür. Isıtma suyu $250 \mathrm{~L}$ hacmindeki su tankının (numara 20) içine yerleştirilen elektriksel isitıcilar (numara 21) ile 1sit1larak, bir boru (numara 15) vasitasiyla test bölümüne taşınmıştır. Isıtma suyunun tanktan test

bölümüne taşınması için bir pompa (numara 19) kullanılmıştır. İçine konik kanatlı 1 sıtıcı borunun yerleştirildiği dış gövde, çevreye olan 1sı kaybını azaltmak için yalıtılmıştır. Ayrıca dış gövdenin iç yüzeyine yerleştirilen perdeler (numara 24) vasıtasıyla havanın 1sıtıcı boru içindeki gidiş yolu uzatılmış ve sıcak yüzeylerle temas süresi arttırılmıştır.
Çalışmada, 1sıtıcı borunun yerleştirildiği dış gövdenin çap $154 \mathrm{~mm}$ ve 1 sııtıcı borunun dış çapı da $27 \mathrm{~mm}$ 'dir. Isitıcı boru uzunluğu ise $900 \mathrm{~mm}$ 'dir. Konik kanatların boru eksenine göre eğilme açısı $60^{\circ}$ 'dir. Isitici boruya monte edilen konik kanatlar arası mesafe (p) 10, 12 ve 15 mm'dir. Çalışılan konik kanatların kanat kalınlığı 0.6 mm'dir. Ayrıca, konik kanatların yükseklikleri $(H) ; \alpha=60^{\circ}$ için $33 \mathrm{~mm}$ 'dir.

Şekil 2'de konik kanatlı 1sıtıcı borunun şematik gösterimi görülmektedir.

Konik kanatlı ısıtıcı boru, dış gövde içinde çapraz hava akışına maruz kalmıştır. Fan vasıtasıyla sekiz farklı hava akış hızında $(2-20 \mathrm{~m} / \mathrm{s})$ deneyler gerçekleştirilmiştir. Deney düzeneğinin tüm kontrolleri PLC programı yardımıyla bilgisayar ortamında yapıııış ve elde edilen ölçüm değerleri de yine bilgisayar ortamında gözlenmiştir.

Ölçülen değerlerin belirsizlikleri; hava tarafı sicaklık $\pm 0.5^{\circ} \mathrm{C}$, hava tarafı boru çap $\pm 2 \mathrm{~mm}$, hava tarafı basınç fark $1 \pm 0.16$ mbar, hava tarafi hız \pm 0.2 $\mathrm{m} / \mathrm{s}$, su tarafı basınç \pm 0.2 mbar, su tarafı sıcaklık \pm $0.1{ }^{\circ} \mathrm{C}$ ve su tarafi akış $\pm 0.4 \mathrm{~L} / \mathrm{h}$ 'dir.

Ayrıca hesaplanan değerlerin belirsizlikleri Kaynak [9] kullanılarak belirlenmiştir. Reynolds sayısının belirsizliği $\% \pm 7.41$ ve Nusselt sayısının belirsizliği ise $\% \pm 7.43$ olarak elde edilmiştir.

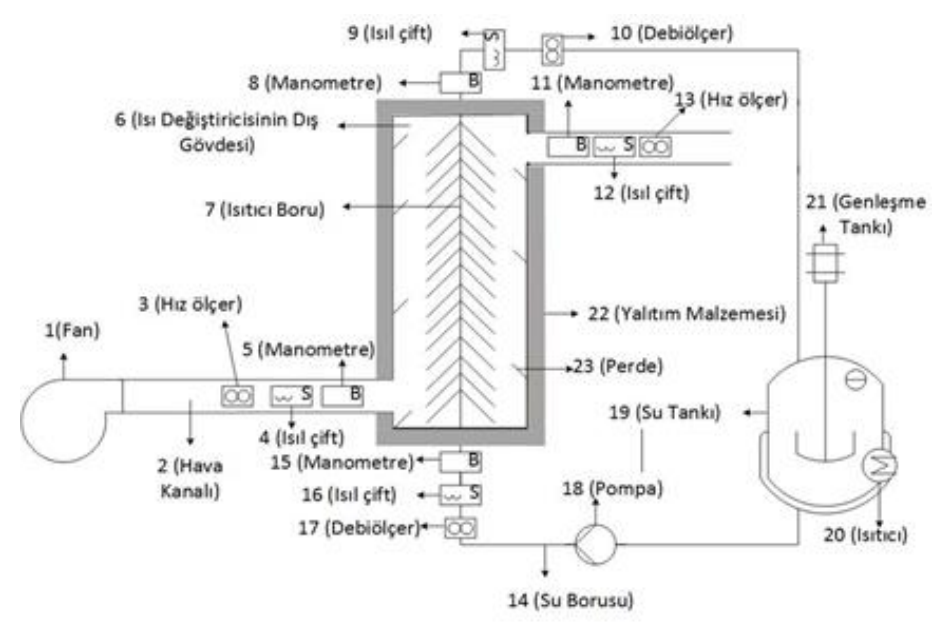

Şekil 1. Deneysel düzeneğin şematik gösterimi.

\section{Matematiksel Formülasyon}

Dış gövde çok iyi yalıtıldığı için çevreye 1s1 kaybı çok küçük oldu. Bundan dolayı aşağıdaki eşitlik yazılabilmektedir:

$\dot{Q}_{s u}=\dot{Q}_{\text {hava }}=\dot{Q}_{c o n v}=\dot{Q}$

burada, 


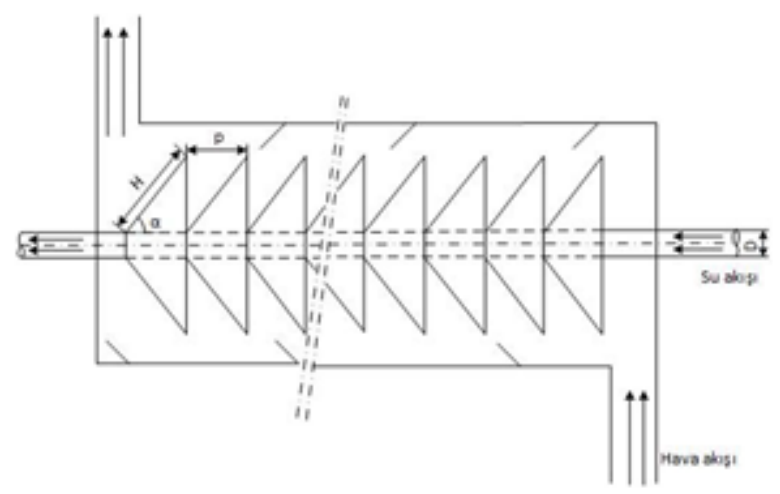

Şekil 2. Konik kanatl ısittcı boru.

$\dot{Q}_{\text {hava }}=\dot{m}_{\text {hava }} \cdot c_{p, \text { hava }} \cdot\left(T_{o, \text { hava }}-T_{i, \text { hava }}\right)$

ve

$\dot{Q}_{s u}=\dot{m}_{s u} \cdot c_{s u} \cdot\left(T_{i, s u}-T_{o, s u}\right)$

Isıtıcı borudan taşınımla 1sı transferi aşağıdaki gibi yazılabilir:

$\dot{Q}_{\text {conv }}=h \cdot A_{\text {toplam }} \cdot\left(T_{s}-T_{\infty}\right)$

burada $A_{\text {toplam }}$ konik kanatlı dairesel borudaki toplam ısı transfer yüzey alanıdır.

$A_{\text {toplam }}=n \cdot\left(A_{s}+\eta_{\text {kanat }} \cdot A_{\text {kanat }}\right)$

burada $A_{s}$ iki kanat arasındaki 1sitıcı boru yüzey alanını ve $\eta_{\text {kanat }}$ kanat verimini temsil etmektedir. Bununla birlikte, $\mathrm{n}$ ise kanat sayısıdır.

Ortalama 1s1 taşınım katsayısı $(h)$ ve ortalama Nusselt sayısı $(\mathrm{Nu})$ aşağıdaki gibi ifade edilmektedir:

$h=\frac{\dot{Q}_{\text {conv }}}{A_{\text {toplam }} \cdot\left(T_{s}-T_{\infty}\right)}$

$N u=\frac{h \cdot D}{k}$

Reynolds sayısı aşağıdaki gibi yazılmaktadır:

$R e=\frac{V_{\max } \cdot D}{V}$

ve

$V_{\text {max }}=\frac{\dot{m}_{\text {hava }}}{\rho_{\text {hava }} \cdot A_{p}}$

burada $V_{\max }$ maksimum hız (iki kanat arasındaki hız) ve $A_{p}$ kanatlar arasındaki akış yönüne dik referans alanıdır.
Isı transfer etkinliği $(\varepsilon)$, sıcak ve soğuk akışkan arasındaki gerçek 1sı transferinin olabilecek maksimum 1S1 transferine oran1 olarak tanımlanmaktadır [10];

$\varepsilon=\frac{\text { gerçek } \text { isı transferi }}{\text { olabilecek maksimum isı transferi }}$

Gerçek 1sı transferi ise sıcak ve soğuk akışkan üzerindeki enerji dengesinden bulunabilir;

$\dot{Q}=\left(\dot{m}_{s u} \cdot c_{s u}\right) \cdot\left(T_{i, s u}-T_{o, s u}\right)=C_{s u} \cdot\left(T_{i, s u}-T_{o, s u}\right)$

ve

$\dot{Q}=\left(\dot{m}_{\text {hava }} \cdot c_{p, \text { hava }}\right) \cdot\left(T_{o, \text { hava }}-T_{i, \text { hava }}\right)=$

$C_{\text {hava }} \cdot\left(T_{o, \text { hava }}-T_{i, \text { hava }}\right)$

Kütlesel debisi $\dot{m}_{s u}\left(\mathrm{~kg} / \mathrm{m}^{3}\right)$ ve özgül 1sis1 $c_{s u}$ $\left(\mathrm{kJ} / \mathrm{kg}^{\circ} \mathrm{C}\right)$ olan sıcak akışkan $T_{i, s u}\left({ }^{\circ} \mathrm{C}\right)$ sıcaklığında test bölümüne girmekte ve $T_{o, s u}\left({ }^{\circ} \mathrm{C}\right)$ sicaklığında çıkmaktadır. Kütlesel debisi $\dot{\mathrm{m}}_{\text {hava }}\left(\mathrm{kg} / \mathrm{m}^{3}\right)$ ve özgül 1S1s1 $c_{p \text {,hava }}\left(\mathrm{kJ} / \mathrm{kg}^{\circ} \mathrm{C}\right)$ olan soğuk akışkan ise $T_{i, s u}$ $\left({ }^{\circ} \mathrm{C}\right)$ sicaklığında girmekte ve $T_{o, s u}\left({ }^{\circ} \mathrm{C}\right)$ sicaklığında çıkmaktadır. $C_{s u}$ ve $C_{\text {hava }}$ ise sirasiyla sicak ve soğuk akışkan 1sıl kapasiteleridir.

Olabilecek maksimum 1sı transferi;

$\dot{Q}_{\text {max }}=(\dot{m} . c)_{\text {min }} \cdot\left(T_{i, h}-T_{i, c}\right)=C_{\text {hava }} \cdot\left(T_{i, s u}-\right.$

$\left.T_{i, \text { hava }}\right) \quad$ (13)

Etkinlik;

$\varepsilon=\frac{\dot{Q}}{\dot{Q}_{\text {max }}}=\frac{C_{s u \cdot\left(T_{i, s u}-T_{o, s u}\right)}}{C_{\text {hava }} \cdot\left(T_{i, s u}-T_{i, \text { hava }}\right)}$

ve

$N T U=\frac{U \cdot A_{\text {toplam }}}{C_{\min }}$

Burada, $U$ - toplam 1s1 transfer katsay1s1 $\left(\mathrm{W} / \mathrm{m}^{2}{ }^{\circ} \mathrm{C}\right)$, $N T U$ - transfer birim sayısidır.

\section{Bulgular ve Tartışma}

Deneysel çalışma, üç farklı kanat aralığı $(10,12$ ve $15 \mathrm{~mm}$ ) için çapraz akış düzenlemesinde gerçekleştirildi. Deneylerde, eğilme açısı $60^{\circ}$ olan konik kanatlar kullanıldı. Isıtıcı akışkan (su) sıcaklığı $65{ }^{\circ} \mathrm{C}$ 'da sabit tutuldu. Isıttılan akışkan (hava) sekiz farklı hava akıș hızında $(2,5,8,10,13$, 15,18 ve $20 \mathrm{~m} / \mathrm{s}$ ) test bölümüne girdi.

Ayrıca deneysel sistemin doğruluğunu göstermek için düz boruya ait deneysel veriler elde edildi. Düz boru için deneysel olarak elde edilen Nusselt sayıları literatürde [10] bulunan Churchill ve Bernstein'in 
korelasyonundan elde edilen Nusselt sayıları ile karşılaştırıldı.

Churchill ve Bernstein' in korelasyonu:

$N u=\frac{h D}{k}=0.3+\frac{0.62 R e^{1 / 2} \operatorname{Pr}^{1 / 3}}{\left[1+(0.4 / P r)^{2 / 3}\right]^{1 / 4}}\left[1+\left(\frac{R e}{282,000}\right)^{5 / 8}\right]^{4 / 5}$

Şekil 3'de, Denklem (17)'den elde edilen Nusselt sayıları ile deneysel sonuçların Nusselt sayılarının karşılaştırılmaları görülmektedir.

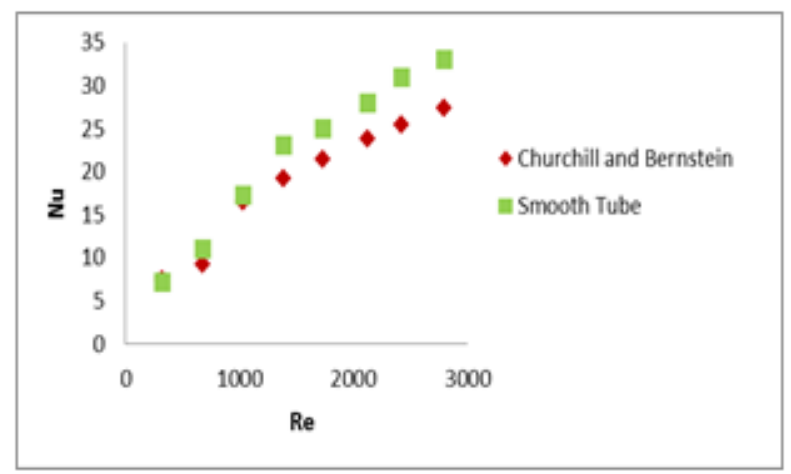

Şekil 3. Düz borunun Nusselt sayılarının doğrulanması.

$\mathrm{Bu}$ çalışmanın deneysel sonuçlarının, Churchill ve Bernstein'in korelasyonundan elde edilen sonuçlar ile $\pm 13 \%$ yaklaşım sağladığı Şekil 3'de görülmektedir.

Şekil 4'de, $\alpha=60^{\circ}$ için farklı kanat aralıklarının ve Reynolds sayısının Nusselt sayısı üzerindeki etkisi gösterilmektedir.

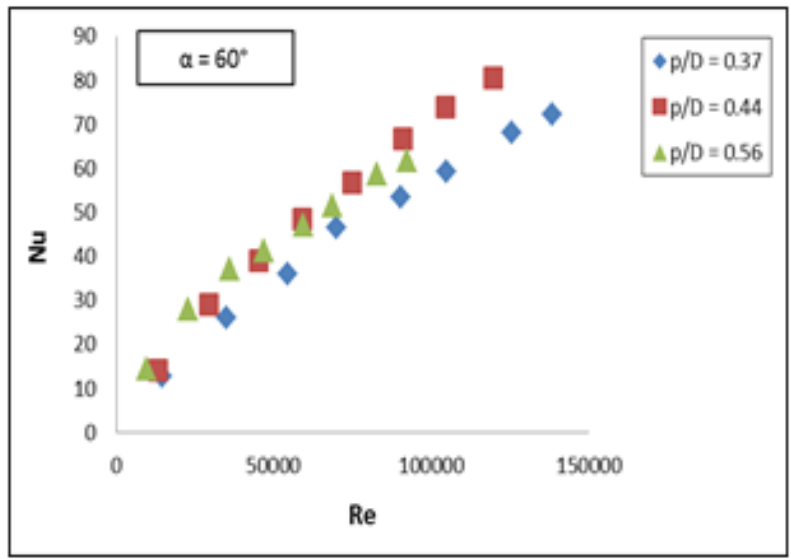

Şekil 4. Kanat aralı̆̆l ve Reynolds sayısının Nusselt sayısı üzerindeki etkisi.

Yaklaşık olarak $R e=50000$ 'e kadar 12 ve $15 \mathrm{~mm}$ kanat aralıklarına ait Nusselt sayılarının hemen hemen birbirine yakın olduğu Şekil 4'de görülmektedir. Ancak, Re > 50000 değerleri için ise $12 \mathrm{~mm}$ kanat aralığındaki Nusselt sayıları en büyük olmaktadır. Tüm Reynolds sayıları için en küçük Nusselt sayıları $10 \mathrm{~mm}$ kanat aralığında elde edilmektedir. Sonuç olarak, $R e>50000$ için 1s1 transferi açısından en iyi kanat aralığının $12 \mathrm{~mm}$ olduğu belirlenmektedir.

Şekil 5'de $\alpha=60^{\circ}$ için basınç düşümü ile Reynolds sayısı ve kanat aralığının değişimi görülmektedir.

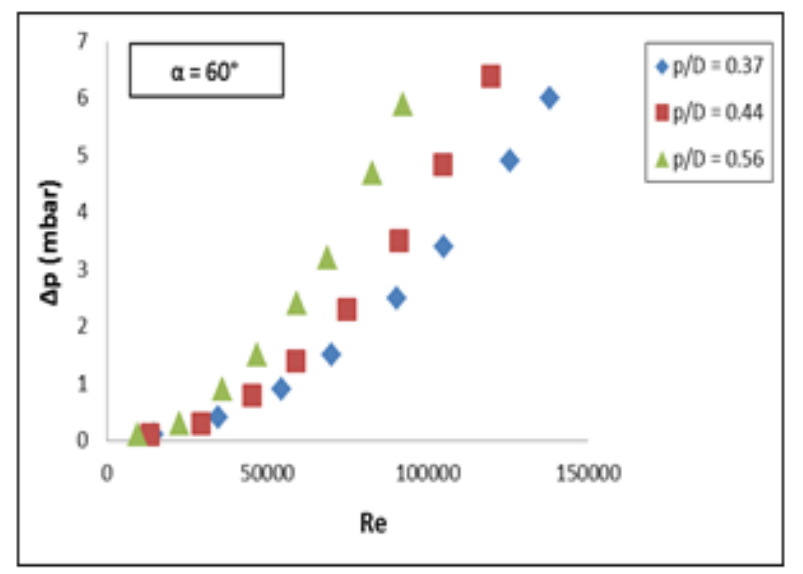

Şekil 5. Basınç düşümünün Reynolds sayısı ile değişimi.

Şekil 5'de de görüldüğü gibi $15 \mathrm{~mm}$ kanat aralığının basınç düşümü diğer kanat aralıklarının basınç düşümüne göre daha büyük olmaktadır. Ancak $R e<50000$ için üç kanat aralığının basınç düşüm değerleri arasındaki fark çok az iken $R e>$ 50000 için ise bu fark büyük olmaktadır.

Şekik 6, üç farklı kanat aralığı için kanat veriminin Reynolds sayısı ile değişimini göstermektedir.

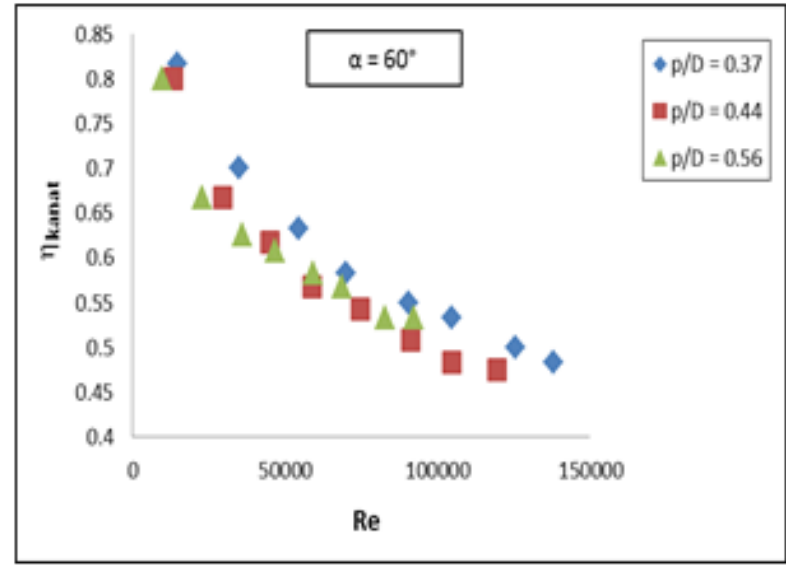

Şekil 6. Kanat veriminin Reynolds sayısı ile değişimi.

Kanat verimi başlıca, kanatın yüzey alanına, 1sı taşınım katsayısına ve yüzey sıcaklığına bağlıdır. Şekil 6'da, Reynolds sayısı arttıkça kanat veriminin azaldığ 1 görülmektedir. Kanat verimindeki azalışın nedeni, kanatlar etrafındaki hava akış hızının artmasıdır. Hava akış hızındaki artış, kısmen kanat dibinden kanat ucuna kadar, düşük yüzey sıcaklığına yol açmaktadır. Sonuç olarak da, daha büyük hava akış hızı, artan 1sı taşınım katsayısından dolayı daha düşük yüzey sıcaklığına ve daha düşük kanat 
verimine sebep olmaktadır. Şekil 6'da görüldüğü gibi, $\alpha=60^{\circ}$ için en yüksek kanat verimi $10 \mathrm{~mm}$ kanat aralığında gerçekleşmektedir.

Şekil 7'de, $\alpha=60^{\circ}$ için etkinlik (c)'in NTU ile değişimi görülmektedir.

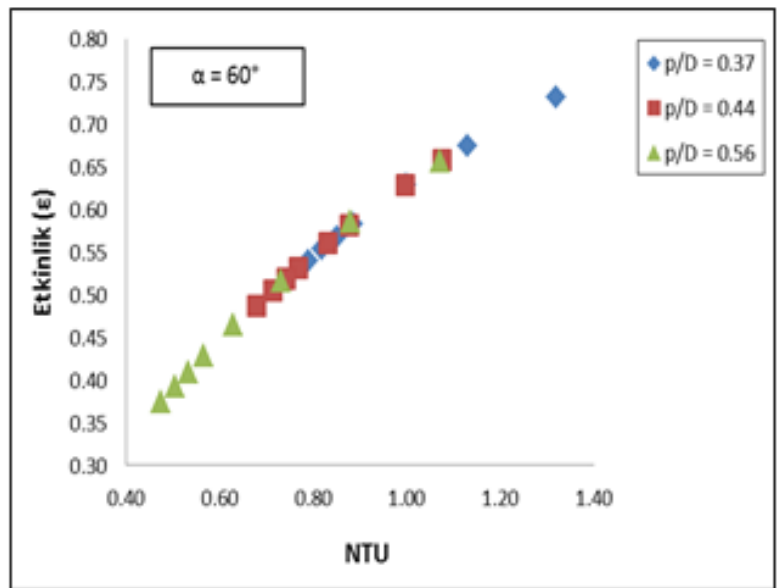

Şekil 7. Ü̧̧ farklı kanat aralığı için etkinliğin (ع) NTU ile değişimi.

Şekil 7'de görüldüğü gibi, $\alpha=60^{\circ}$ için $N T U$ arttıkça etkinlikte $(\varepsilon)$ artmaktadır. Ayrıca, NTU = 0.7 'e kadar, $15 \mathrm{~mm}$ kanat aralığına ait etkinlik değeri en düşük iken $0.7<N T U<1$ için tüm kanat aralıklarının etkinlikleri hemen hemen yakın olmaktadır. $N T U>1$ için ise, $10 \mathrm{~mm}$ kanat aralığı en büyük etkinlik değerine sahiptir.

\section{Sonuçlar}

$\mathrm{Bu}$ çalışmadan elde edilen deneysel sonuçlar aşağıda belirtilmektedir:

1. $R e>50000$ için 1 sı transferi açısından en iyi kanat aralığ $12 \mathrm{~mm}$ 'dir.

2. $15 \mathrm{~mm}$ kanat aralığının basınç düşümü diğer kanat aralıklarının basınç düşümüne göre daha büyüktür.

3. En yüksek kanat verimi, $10 \mathrm{~mm}$ kanat aralığında gerçekleşmektedir.

4. $N T U=0.7$ ' $\mathrm{kadar}, 15 \mathrm{~mm}$ kanat aralığına ait etkinlik değeri en düşük iken $0.7<N T U$ $<1$ için tüm kanat aralıklarının etkinlikleri hemen hemen yakın olmaktadır. NTU $>1$ için ise, $10 \mathrm{~mm}$ kanat aralığ 1 en büyük etkinlik değerine sahiptir.

\section{Teşekkür}

Yazar, ICCESEN 2016 sempozyumu için finansal destek sağlayan, Pamukkale Üniversitesi, Bilimsel Araştırma Projeleri Birimine teşekkürlerini sunmaktadır.

\section{Simgeler}

\begin{tabular}{|c|c|}
\hline $\begin{array}{l}A_{\text {toplam }} \\
A_{S}\end{array}$ & $\begin{array}{l}\text { toplam } 1 \text { sı transfer yüzey alanı }\left(\mathrm{m}^{2}\right) \\
\text { iki kanat arasındaki 1sıtıcı boru yüzey } \\
\text { alanı }\left(\mathrm{m}^{2}\right)\end{array}$ \\
\hline$A_{\text {kanat }}$ & boru üzerindeki konik kanatın alanı $\left(\mathrm{m}^{2}\right)$ \\
\hline$A_{p}$ & $\begin{array}{l}\text { kanatlar arasındaki akış yönüne dik } \\
\text { referans alanı }\left(\mathrm{m}^{2}\right)\end{array}$ \\
\hline$c_{p, \text { hava }}$ & havanın özgül 1sınma 1sısı $\left(\mathrm{kJ}^{\prime} \mathrm{kg}^{\circ} \mathrm{C}\right)$ \\
\hline$c_{s u}$ & $\begin{array}{l}\text { suyun özgül 1sinma 1sisı }\left(\mathrm{kJ}^{\prime} \mathrm{kg}^{\circ} \mathrm{C}\right) \\
\text { 1s1l kapasite }\left(\mathrm{W}^{\circ} \mathrm{C}\right)\end{array}$ \\
\hline$C_{\text {hava }}$ & havanın 1 sil kapasitesi $\left(\mathrm{W} /{ }^{\circ} \mathrm{C}\right)$ \\
\hline$C_{s u}$ & suyun isıl kapasitesi $\left(\mathrm{W} /{ }^{\circ} \mathrm{C}\right)$ \\
\hline$D$ & 1stıcı boru diş çapı $(m)$ \\
\hline$H$ & konik kanat yüksekliği $(m)$ \\
\hline$h$ & 1Sı taşınım katsayısı $\left(\mathrm{W} / \mathrm{m}^{2} \mathrm{~K}\right)$ \\
\hline$k$ & 1sı iletim katsayısı $\left(\mathrm{W} / \mathrm{m}^{\circ} \mathrm{C}\right)$ \\
\hline$L$ & 1sıttıcı boru uzunluğu $(m)$ \\
\hline$\dot{m}_{\text {hava }}$ & havanın kütlesel debisi $(\mathrm{kg} / \mathrm{s})$ \\
\hline$\dot{m}_{s u}$ & suyun kütlesel debisi $(\mathrm{kg} / \mathrm{s})$ \\
\hline$N T U$ & transfer birim sayısı \\
\hline$n$ & konik kanat sayısı \\
\hline $\mathrm{Nu}$ & Nusselt sayısı \\
\hline $\operatorname{Pr}$ & Prandtl sayısı \\
\hline$p$ & konik kanatlar arası mesafe $(\mathrm{m})$ \\
\hline$\dot{Q}$ & gerçek 1s1 transferi $(W)$ \\
\hline$\dot{Q}_{\max }$ & olabilecek maksimum 1s1 transferi $(W)$ \\
\hline$\dot{Q}_{\text {conv }}$ & taşınımla 1sı transferi $(W)$ \\
\hline $\operatorname{Re}$ & Reynolds sayısı \\
\hline$T_{i, h a v a}$ & havanın test bölümüne giriş sıcaklığ $1\left({ }^{\circ} \mathrm{C}\right)$ \\
\hline$T_{o, h a v a}$ & $\begin{array}{l}\text { havanın test bölümünden çıkış sıcaklığı } \\
\left({ }^{\circ} \mathrm{C}\right)\end{array}$ \\
\hline$T_{i, s u}$ & suyun test bölümüne giriş sıcaklığı $\left({ }^{\circ} \mathrm{C}\right)$ \\
\hline$T_{o, s u}$ & suyun test bölümünden çıkış sıcaklığı $\left({ }^{\circ} C\right)$ \\
\hline$T_{S}$ & 1sitıcı boru yüzey sıcaklıği $\left({ }^{\circ} \mathrm{C}\right)$ \\
\hline$T_{\infty}$ & 1sitılmış hava sicaklığg $\left({ }^{\circ} \mathrm{C}\right)$ \\
\hline$t$ & konik kanat kalınlığg $(m)$ \\
\hline$U$ & toplam $1 \mathrm{~s} 1$ transfer katsayıs $\left(\mathrm{W} / \mathrm{m}^{2 \circ} \mathrm{C}\right)$ \\
\hline$V_{\max }$ & maksimum hız $(\mathrm{m} / \mathrm{s})$ \\
\hline$V_{i, \text { hava }}$ & test bölümüne hava giriş hızı $(\mathrm{m} / \mathrm{s})$ \\
\hline
\end{tabular}

\section{Yunanca Simgeler}

$\begin{array}{ll}v & \text { kinematic viskozite }\left(\mathrm{m}^{2} / \mathrm{s}\right) \\ \mu & \text { dinamik viskozite }(\mathrm{kg} / \mathrm{ms}) \\ \alpha & \text { konik kanat eğilme açısı }\left(^{\circ}\right) \\ \varepsilon & \text { etkinlik } \\ \eta_{\text {kanat }} & \text { konik kanat verimi } \\ \Delta p & \text { basıç düşümü }(\mathrm{mbar})\end{array}$

\section{Alt Simgeler}

hava hava tarafi 


$\begin{array}{ll}\text { conv } & \text { taşınım } \\ i & \text { giriş } \\ o & \text { çıkış } \\ s & \text { boru duvarı } \\ s u & \text { su tarafı }\end{array}$

\section{Kaynaklar}

[1] H. E. Ahmed, M. I. Ahmed, M. Z. Yusoff "Heat transfer enhancement in a triangular duct using compound nanofluids and turbulators" Applied Thermal Engineering. 91 (2015) 191-201.

[2] L. Tian, B. Liu, C. Min, J. Wang, Y. He "Study on the effect of punched holes on flow structure and heat transfer of the plain fin with multi - row delta winglets" Heat Mass Transfer. 51 (2015) 1523 1536.

[3] H. M. Şahin, E. Baysal, A. R. Dal "Experimental and Numerical Investigation of Thermal Characteristics of a Novel Concentric Type Tube Heat Exchanger with Turbulators" International Journal of Energy Research. 37 (2013) 1088-1102.

[4] G. Yakar, R. Karabacak "Investigation of Thermal Performance of Perforated Finned Heat Exchangers" Experimental Heat Transfer. 28 (2015) 354-365.

[5] P. Promvonge, S. Tamna, M. Pimsarn, C. Thianpong "Thermal Characterization in a Circular Tube Fitted with Inclined Horseshoe Baffles" Applied Thermal Engineering. 75 (2015) 1147-1155.

[6] A. R. Anvari, R. Lotfi, A. M. Rashidi, S. Sattari "Experimental Research on Heat Transfer of Water in Tubes with Conical Ring Inserts in Transient Regime" International Communications in Heat and Mass Transfer. 38 (2011) 668-671.

[7] D. H. Lee, J. M Jung, J. H. Ha, Y. I. Cho "Improvement of Heat Transfer with Perforated Circular Holes in Finned Tubes of Air Cooled Heat Exchanger" International Communications Heat Mass Transfer. 39 (2012) 161-166.

[8] M. Yaghoubi, M. Mandavi "An Investigation of Natural Convection Heat Transfer from a Horizontal Cooled Finned Tube" Experimental Heat Transfer. 26 (2013) 343-359.

[9] R. J. Moffat "Describing the Uncertainties in Experimental Results" Experimental Thermal and Fluid Science. 1 (1988) 3-17.

[10] Y. A. Çengel "Heat and Mass Transfer: A Practical Approach" 3rd ed. McGraw - Hill, 2006. 